\title{
Experience-based surgical approach to pancreatic mucinous cystic neoplasms with ovarian-type stroma
}

\author{
CHANG MOO KANG ${ }^{1,2}$, AKIRA MATSUSHITA ${ }^{3}$, HO KYOUNG HWANG ${ }^{1,2}$, YOKO MATSUDA ${ }^{4}$, \\ HYUNKI KIM $^{5}$, YOSHIHARU NAKAMURA ${ }^{3}$ and WOO JUNG LEE ${ }^{1,2}$
}

\begin{abstract}
${ }^{1}$ Department of Surgery, Yonsei University College of Medicine; ${ }^{2}$ Pancreaticobiliary Cancer Clinic, Institute of Gastroenterology, Severance Hospital, Yonsei University College of Medicine, Seoul 03722, Republic of Korea; Departments of ${ }^{3}$ Gastrointestinal and Hepato-Biliary-Pancreatic Surgery, and ${ }^{4}$ Integrative Oncological Pathology, Nippon Medical School, Tokyo 113-8603, Japan; ${ }^{5}$ Department of Pathology, Yonsei University College of Medicine, Seoul 03722, Republic of Korea
\end{abstract}

Received June 13, 2016; Accepted August 8, 2017

DOI: $10.3892 / \mathrm{ol} .2017 .7627$

\begin{abstract}
The present study aimed to elucidate the clinicopathological characteristics of resected mucinous cystic neoplasm (MCN) with ovarian-type stroma and identify a surgical approach for MCN treatment, on the basis of Republic of Korean (Yonsei University College of Medicine, Seoul, South Korea) and Japanese (Nippon Medical School, Tokyo, Japan) bi-institutional collaboration. The present study retrospectively reviewed $55 \mathrm{MCNs}$ with ovarian-type stroma using pathological re-examination. Clinicopathological features and preoperative clinical parameters were evaluated to predict malignant alterations in MCNs. The proportion of surgically treated MCNs has recently been increasing. All patients included in the present study were female, with a mean age of $47.9 \pm 13.3$ years. Mural nodules were noted in 8 patients $(14.5 \%)$ and the mean cyst size was $6.1 \pm 4.2 \mathrm{~cm}$. A total of 9 patients $(16.4 \%)$ were identified to exhibit non-invasive mucinous cystadenocarcinoma. The number of patients with small tumors $\left(\mathrm{R}^{2}=-0.079, \mathrm{P}=0.038\right)$ and asymptomatic pancreatic MCNs $(\mathrm{P}=0.022)$ was significantly increased $(\mathrm{P}<0.05)$, which resulted in the more frequent application of minimally invasive surgery $(\mathrm{P}<0.001)$. During the follow-up period (mean, 51.6 months; range, 1.1-242.8 months), no recurrence or tumor-associated mortality was identified. The presence of mural nodules $(\mathrm{P}=0.002)$ and a tumor size $\geq 4.5 \mathrm{~cm}(\mathrm{P}=0.027)$ were identified as potential clinical parameters for predicting
\end{abstract}

Correspondence to: Professor Woo Jung Lee, Department of Surgery, Yonsei University College of Medicine, 50 Yonsei, Seodaemun, Seoul 03722, Republic of Korea

E-mail:wjlee@yuhs.ac

Professor Yoshiharu Nakamura, Department of Gastrointestinal and Hepato-Biliary-Pancreatic Surgery, Nippon Medical School, 1-1-5 Sendagi, Bunkyo, Tokyo 113-8603, Japan

E-mail: keishun@nms.ac.jp

Key words: mucinous cystic neoplasm, laparoscopic, robotic, pancreatectomy malignant transformation. The significance of mural nodules in predicting malignant transformation was increased in large MCNs $(\geq 4.5 \mathrm{~cm})$ of the pancreas compared with small MCNs $(<4.5 \mathrm{~cm})(\mathrm{P}=0.002)$. Overall, non-invasive pancreatic MCNs are not aggressive, and minimally invasive pancreatectomy may be an effective approach for suitable patients.

\section{Introduction}

With improvements in socioeconomic conditions, individuals have developed an increased concern for their personal health. As a result, routine medical check-ups and use of highly available imaging procedures have led to the increased diagnosis of asymptomatic pancreatic cystic lesions worldwide (1). A cystic tumor of the pancreas is pathologically heterogeneous and accounts for between 10 and $15 \%$ of cystic lesions of the pancreas (2). Pancreatic cystic tumors are biologically diverse and typically categorized as a serous cystic neoplasm (SCN), a mucinous cystic neoplasm ( $\mathrm{MCN})$, an intraductal papillary mucinous neoplasm (IPMN) or a solid pseudopapillary tumor of the pancreas (SPT). MCN of the pancreas is a notable pathological entity of the pancreas, histologically composed of inner epithelial mucin-secreting cells and a surrounding dense ovarian-type stroma. However, there has been confusion between MCN and IPMN, as ovarian-type stroma was not previously regarded as a diagnostic criterion for MCN (3). However, the World Health Organization classification in 2000 emphasized the significance of ovarian stroma for the diagnosis of MCNs $(4,5)$ and the consensus meeting of the International Association of Pancreatology, held in Sendai Japan, restricted the term MCN to a neoplasm with the presence of ovarian stroma (6).

According to a Korean multi-institutional survey (7), MCN was identified to be the second most common type of neoplastic cyst of the pancreas in Korea. The majority of MCNs are identified in middle-aged females, and are typically located in the body and tail of the pancreas (8-10). MCNs have been demonstrated to exhibit malignant potential, but a good prognosis. However, the diagnosis of pancreatic $\mathrm{MCN}$ remains rare, comprising between 1 and $2 \%$ all pancreatic tumors (11). Surgical experience of 163 resected MCNs was previously 
analyzed by one study (12), however, only a limited number of other studies have described surgical experiences with MCNs.

In the present study, surgical experience with MCN of the pancreas was reviewed, on the basis of Korean (Yonsei University College of Medicine; YUCM) and Japanese (Nippon Medical School; NMS) bi-institutional collaboration. In addition, the present study aimed to identify the clinicopathological characteristics of pancreatic MCNs detected between January 1990 and December 2012. Furthermore, the pre-surgical clinical parameters that are predictive of malignant transformation were analyzed to identify effective surgical management of $\mathrm{MCN}$ of the pancreas.

\section{Materials and methods}

Patients. Between January 1990 and December 2012, 68 patients (YUCM, 45 patients; NMS, 23 patients) underwent pancreatectomy for non-invasive $\mathrm{MCN}$ of the pancreas. Among patients who underwent surgical resection of known MCN, cases that exhibited MCNs were reviewed. A total of 55 out of 68 cases, those that exhibited mucin-secreting epithelial cells and a dense ovarian stroma, were selected for the present study. All patients included in the present study were female, with a mean age of 47.9 \pm 13.3 years (range, 24-75 years). All patients were diagnosed and classified using the International Agency for Research on Cancer/World Health Organization 2010 classification (13).

Medical records review. The available medical records were reviewed to identify the general characteristics, clinical presentations, surgical outcomes and pathological results of the patients. Chronological alterations in MCNs of the pancreas were analyzed and grouped as follows: Period 1, between January 1990 and December 1999; period 2, between January 2000 and December 2006; and period 3, between January 2007 and December 2012. In addition, patients were divided into the following two groups: The minimally invasive approach group (MIS), for those who underwent laparoscopic or robot-assisted surgery; and the open surgery group (conventional). Subsequently, clinicopathological characteristics of MCNs and perioperative outcomes were reviewed. A postoperative pancreatic fistula (POPF) was defined according to the guidelines of the International Study Group on Pancreatic Fistulas (ISGPF) (14). Furthermore, postoperative bleeding was defined by the criteria proposed by the ISGPF (15). Mortality was defined as mortality within 30 days of surgery whether in or outside of the hospital. Follow-up data was reviewed for recurrence or tumor-specific mortality.

Statistical analysis. Categorical variables were presented as frequency and percentage, and continuous variables as the mean \pm standard deviation. A receiver operating characteristic curve was used to estimate the optimal tumor size and predict the malignant transformation of $\mathrm{MCN}$ of the pancreas. The $\chi^{2}$ test (Fisher's exact test), Mann-Whitney test and linear regression analysis were used for statistical assessment of associations. $\mathrm{P}<0.05$ was considered to indicate a statistically significant difference. All statistical analyses were performed using IBM SPSS v.22.0 (IBM Corp., Armonk, NY, USA).

\section{Results}

Patient characteristics. For the 68 patients, 13 pathological specimens $(13 / 68,19.1 \%)$ were revealed not to be MCNs (10/13, IPMNs; 3/13, pancreatic intraepithelial neoplasia cases). Excluding the 13 patients, a total of 55 patients with non-invasive MCN of the pancreas were analyzed. All patients were female, with a mean age of $47.9 \pm 13.3$ years. A total of 19 patients $(19 / 55,34.5 \%)$ were identified to exhibit a pancreatic cystic tumor via routine medical check-up. Abdominal discomfort $(15 / 55,27.3 \%)$ was the most common clinical symptom. General weakness and weight loss was demonstrated in 9 patients (16.4\%) and an abdominal mass was identified in 3 patients $(5.5 \%)$. Diabetes mellitus was demonstrated in 4 patients $(7.3 \%)$ and 6 patients $(10.9 \%)$ exhibited an extra-pancreatic malignant disease, including breast cancer in 2 patients, cervical cancer in 1 patient, thyroid cancer in 1 patient, hepatocellular carcinoma in 1 patient and early gastric cancer in 1 patient.

Preoperative imaging study. All patients received abdominal computed tomography, whereas abdominal endoscopic ultrasound scans, magnetic resonance imaging and endoscopic retrograde cholangiopancreatography were selectively performed for preoperative evaluation to characterize cystic tumors if mural nodules appeared in a preoperative computed tomography scan. There was no definitive radiological evidence of local invasiveness in all patients, but 8 patients $(8 / 55,14.5 \%)$ exhibited an intracystic solid component (mural nodule). The mean size of the surgical specimen was $6.1 \pm 4.2 \mathrm{~cm}$ and the majority of cystic tumors $(52 / 55,94.5 \%)$ were located in the distal pancreas (body and tail of the pancreas), with only 3 $(3 / 55,5.5 \%)$ in the pancreatic head.

Selection of surgical procedures. It was demonstrated that distal pancreatectomy with or without splenectomy was the most common type of surgical procedure for treating MCN of the pancreas $(46 / 55,83.6 \%)$. Cyst enucleation was performed in 5 patients $(5 / 55,9.1 \%)$, and pancreatoduodenectomy was performed in 3 patients $(3 / 55,5.5 \%)$. A laparoscopic or robot-assisted minimally invasive approach was applied in 31 patients $(31 / 55,56.4 \%)$. When considering cases of distal pancreatectomy, there were significant different clinical characteristics between the two institutions (Table I). In NMS, the minimally invasive surgical approach was performed more frequently compared with the conventional surgical approach $(\mathrm{P}=0.005)$. However, the spleen-preserving procedure was more frequent in YUCM $(\mathrm{P}=0.069)$. Comparing the data from the two institutions, tumor size was demonstrated to be similar; however, tumor location and associated symptoms were identified to be significantly different $(\mathrm{P}<0.05$; Table I).

Postoperative outcomes. There was no postoperative mortality. A POPF was developed in 10 patients $(10 / 55,18.2 \%$; grade B, $\mathrm{n}=9$; and grade $\mathrm{C}, \mathrm{n}=1$ ) and postoperative hemorrhage was identified in 1 patient $(1 / 55,1.8 \%)$. MCN-adenoma was identified in 15 patients $(27.3 \%)$ and MCN-borderline in 20 patients $(36.4 \%)$. Focal non-invasive carcinoma was identified in 9 patients $(9 / 55,16.4 \%)$. 
Table I. Clinical characteristics of distal pancreatectomy in two institutions.

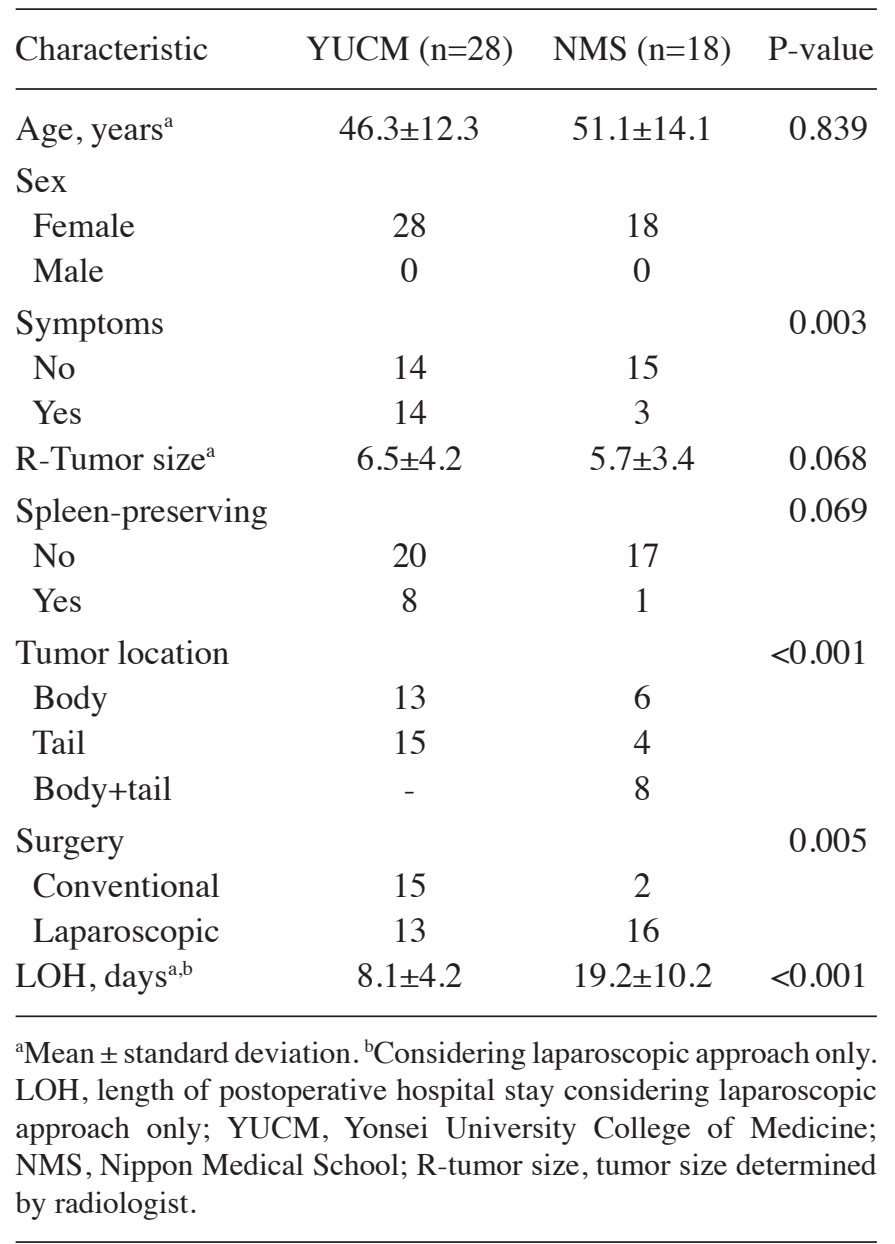

Chronological alterations in surgically resected MCNs of the pancreas. A total of 11 patients $(20 \%)$ were surgically treated for MCN of the pancreas in period 1, 16 patients $(29.1 \%)$ in period 2 and 28 patients $(50.9 \%)$ in period 3 . The number of treated patients per year in period 3 increased by 5 -fold compared with those in period 1 (Fig. 1). Tumor size generally decreased over all periods. (Fig. 2) [tumor size $=(-0.072) \times$ case sequence (order of operation) $+8.088 ; \mathrm{P}=0.038]$. Therefore, asymptomatic patients were more frequently found through routine medical check-up $(\mathrm{P}=0.022)$, and minimally invasive surgery, such as the laparoscopic and robot-assisted approach, was frequently applied in the recent surgical period $(\mathrm{P}<0.001)$. Furthermore, a significant increase was demonstrated in spleen-preserving surgery, when performing distal pancreatectomy, between periods $(\mathrm{P}=0.026$; Table II).

Comparative analysis between conventional and minimally invasive surgical approaches. A total of 31 patients (56.4\%) underwent minimally invasive pancreatectomy for MCN of the pancreas. Conventional laparoscopic approach was performed in 26 patients $(26 / 55,47.3 \%)$ and robot-assisted distal pancreatectomy was conducted in 5 patients $(5 / 55$, 9.1\%). Compared with the conventional group, the MIS group demonstrated an increased number of asymptomatic patients $(\mathrm{P}=0.059)$, a smaller tumor size (radiological size,
Table II. Alterations in the clinical characteristics of pancreatic mucinous cystic neoplasms, according to the time of surgery.

\begin{tabular}{|c|c|c|c|c|}
\hline \multirow[b]{2}{*}{ Characteristic } & \multicolumn{3}{|c|}{ Period } & \multirow[b]{2}{*}{ P-value } \\
\hline & 1 & 2 & 3 & \\
\hline Age, years ${ }^{\mathrm{a}}$ & $47.3 \pm 14.3$ & $51.1 \pm 10.9$ & $46.5 \pm 14.4$ & 0.545 \\
\hline Sex & & & & 0.545 \\
\hline Male & 0 & 0 & 0 & \\
\hline Female & 11 & 16 & 28 & \\
\hline Symptoms & & & & 0.022 \\
\hline No & 2 & 12 & 19 & \\
\hline Yes & 9 & 4 & 9 & \\
\hline Tumor size, $\mathrm{cm}^{\mathrm{a}}$ & $8.0 \pm 6.4$ & $6.2 \pm 3.8$ & $5.2 \pm 3.0$ & 0.250 \\
\hline $\begin{array}{l}\text { Malignant } \\
\text { transformation }\end{array}$ & & & & 0.113 \\
\hline No & 9 & 11 & 26 & \\
\hline Yes & 2 & 5 & 2 & \\
\hline Surgery & & & & $<0.001$ \\
\hline Conventional & 11 & 10 & 3 & \\
\hline Minimally invasive & - & 6 & 25 & \\
\hline Spleen-preserving ${ }^{\mathrm{a}, \mathrm{b}}$ & & & & 0.026 \\
\hline No & 5 & 13 & 19 & \\
\hline Yes & 0 & 0 & 9 & \\
\hline
\end{tabular}

${ }^{\mathrm{a}}$ Mean \pm standard deviation. ${ }^{\mathrm{b}}$ Considering distal pancreatectomy only. Period 1, January 1991-December 1991; period 2, January 2000-December 2006; period 3, January 2007-December 2012. Conventional, open surgery; minimally invasive, laparoscopic or robot-assisted surgery.

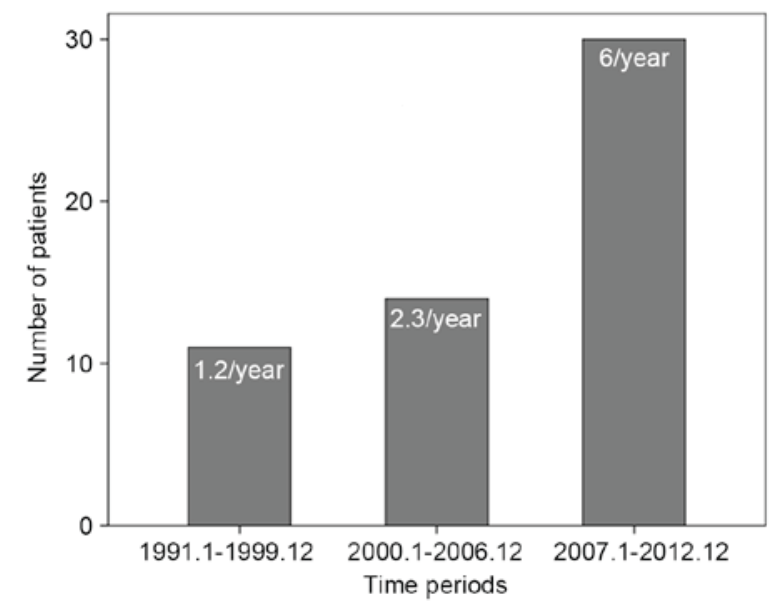

Figure 1. Number of surgically treated patients with mucinous cystic neoplasms according to three different time periods.

$7.4 \pm 5.32$ vs. $4.9 \pm 2.8 \mathrm{~cm}, \mathrm{P}=0.045$; pathological size, $7.3 \pm 5.9$ vs. $4.6 \pm 2.1 \mathrm{~cm}, \mathrm{P}=0.044)$ and an increased surgical duration $(208.3 \pm 95.4$ vs. $316.3 \pm 152.1 \mathrm{~min}, \mathrm{P}=0.004)$. Notably, hospital stay was similar between the two groups $(12.7 \pm 6.7$ vs. 13.8 \pm 9.6 days, $\mathrm{P}=0.412)$. However, it was demonstrated that the post-surgical hospital stay was distinct between the 
Table III. Comparative analysis between conventional open and minimally invasive surgical approaches.

\begin{tabular}{|c|c|c|c|}
\hline Feature & Conventional & $\begin{array}{l}\text { Minimally } \\
\text { invasive }\end{array}$ & P-value \\
\hline Age, years ${ }^{\mathrm{a}}$ & $48.1 \pm 12.9$ & $48.1 \pm 14.4$ & 0.773 \\
\hline \multicolumn{4}{|l|}{ Sex } \\
\hline Male & 0 & 0 & \\
\hline Female & 24 & 31 & \\
\hline Symptom & & & 0.059 \\
\hline No & 11 & 22 & \\
\hline Yes & 13 & 9 & \\
\hline R tumor size, $\mathrm{cm}^{\mathrm{a}}$ & $7.4 \pm 5.2$ & $4.9 \pm 2.8$ & 0.045 \\
\hline $\mathrm{P}$ tumor size, $\mathrm{cm}^{\mathrm{a}}$ & $7.3 \pm 5.9$ & $4.6 \pm 2.1$ & 0.044 \\
\hline Location & & & 0.077 \\
\hline Proximal & 3 & - & \\
\hline Distal & 21 & 31 & \\
\hline \multicolumn{4}{|l|}{ Type of resection } \\
\hline $\mathrm{EN}$ & 3 & 2 & \\
\hline SpDP & 1 & 8 & \\
\hline DPS & 16 & 21 & \\
\hline PD & 3 & - & \\
\hline $\mathrm{CP}$ & 1 & - & \\
\hline Surgical duration, $\min ^{\mathrm{a}}$ & $208.3 \pm 95.4$ & $316.3 \pm 152.1$ & 0.004 \\
\hline Bleeding amount, $\mathrm{ml}^{\mathrm{a}}$ & $726.8 \pm 211$ & $331.6 \pm 426.3$ & 0.059 \\
\hline Transfusion & & & 0.863 \\
\hline No & 22 & 28 & \\
\hline Yes & 2 & 3 & \\
\hline POPF Grade B & & & 0.336 \\
\hline No & 21 & 24 & \\
\hline Yes & 3 & 7 & \\
\hline LOH, days & $12.7 \pm 6.7$ & $13.8 \pm 9.6$ & 0.079 \\
\hline YUCM & $12.4 \pm 6.9$ & $8.1 \pm 4.2$ & 0.45 \\
\hline NMS & $16.5 \pm 2.1$ & $19.2 \pm 10.2$ & 0.941 \\
\hline
\end{tabular}

${ }^{a}$ Mean \pm standard deviation. MIS, minimally invasive surgery; EN, enucleation; SpDP, spleen-preserving distal pancreatectomy; DPS, distal pancreatosplenectomy; PD, pancreaticoduodenectomy; $\mathrm{CP}$, central pancreatectomy; $\mathrm{LOH}$, length of hospital stay; R, tumor size measured by radiologist; $\mathrm{P}$, tumor size measured by pathologist; POPF, postoperative pancreatic fistula; YUCM, Yonsei University College of Medicine; NMS, Nippon Medical School.

two groups when considering individual institutional analysis (YUCM, 12.4 \pm 6.9 vs. 8.1 \pm 4.2 days, $\mathrm{P}=0.045$; NMS, $16.5 \pm 2.1$ vs. 19.2 \pm 10.2 days, $\mathrm{P}=0.394$ ) (Table III).

Preoperative prediction of malignant transformation. Malignant transformation (focal non-invasive mucinous cystadenocarcinoma) was observed in 9 patients $(9 / 55,16.4 \%)$. Follow-up data was available for 51 patients $(51 / 55,92.7 \%)$ and 4 patients were lost to follow-up. The mean follow-up duration was 51.6 months (range, 1.1-242.8 months). Neither recurrence nor tumor-associated mortality was observed in benign,

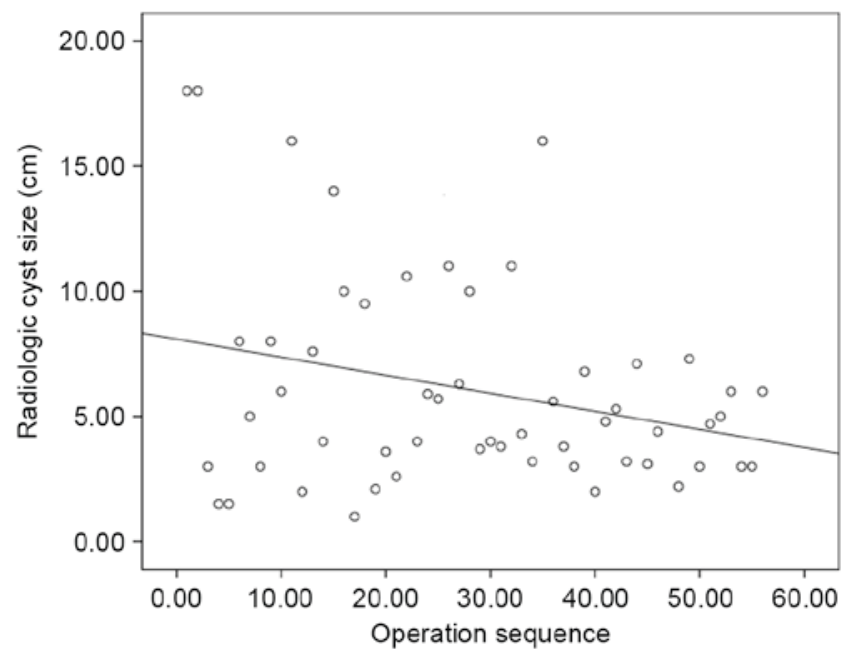

Figure 2. Correlation between order of surgical procedures and tumor size of pancreatic mucinous cystic neoplasm $\left(\mathrm{R}^{2}=-0.079, \mathrm{P}=0.038\right)$.

borderline MCNs or MCNs with malignant transformation. A tumor size of $>4.5 \mathrm{~cm}$ was identified to predict malignant transformation of MCN with an $88.9 \%$ sensitivity and a $45.7 \%$ false-positive rate (1-specificity), and this threshold value was statistically significant in the preoperative prediction of malignant transformation [area under the curve (AUC), 0.719; $\mathrm{P}=0.039$; Fig. 3]. Radiological tumor size $(\geq 4.5 \mathrm{~cm} ; \mathrm{P}=0.027)$ and intra-cystic solid portions (mural nodule; $\mathrm{P}=0.002$ ) were identified as important preoperative clinical parameters to predict malignant transformation (Table IV). In particular, the significance of mural nodules in predicting malignant transformation was significant in large MCNs of the pancreas $(\geq 4.5 \mathrm{~cm} ; \mathrm{P}=0.002$; Table $\mathrm{V})$.

\section{Discussion}

Pancreatic cancer is known to be one of the most lethal gastrointestinal malignant diseases. Overall survival is $<5 \%$ and complete surgical resection is the most effective treatment approach (16). However, between 10 and $15 \%$ of patients with pancreatic cancer may be surgical candidates and the long-term survival rate is between 10 and $20 \%$ with surgical resection (17-19). Therefore, early detection and prevention are critical to improve the outcome of pancreatic cancer. MCN of the pancreas is potentially malignant and previous studies have suggested the presence of adenoma-carcinoma sequences $(9,20,21)$. Although the outcome of mucinous cystadenocarcinoma is known to be superior to that of ductal adenocarcinoma of the pancreas $(22,23)$, the 5-year disease-specific survival rate for patients with invasive mucinous cystadenocarcinoma is $\sim 30 \%$ (10). Therefore, complete resection of the tumor prior to the development of invasive cancer is considered an important surgical goal in treating MCNs of the pancreas.

Pancreatic MCN is not an aggressive cancer $(12,24)$. As described in the present study, in the follow-up of patients available (mean, 51.6 months (range, 1.1-242.8 months), neither recurrence nor tumor-specific mortality was observed in all MCNs with malignant transformation. Therefore, pancreatic surgeons should consider a patient's quality of life following 
Table IV. Prediction of malignant transformation of non-invasive mucinous cystic neoplasms of the pancreas.

\begin{tabular}{lrrr}
\hline & \multicolumn{2}{c}{$\begin{array}{c}\text { Malignant } \\
\text { transformation }\end{array}$} & \\
\cline { 2 - 3 } Characteristic & No & Yes & P-value \\
\hline Tumor size $<4.5 \mathrm{~cm}$ & 25 & 1 & 0.027 \\
Tumor size $\geq 4.5 \mathrm{~cm}$ & 21 & 8 & \\
Mural nodule $(-)$ & 43 & 4 & 0.002 \\
Mural nodule (+) & 3 & 5 & \\
Total & 46 & 9 & \\
\hline
\end{tabular}

Table V. Significance of mural nodules in predicting malignant transformation according to tumor size.

\begin{tabular}{lrrr}
\hline & \multicolumn{2}{c}{$\begin{array}{c}\text { Malignant } \\
\text { transformation }\end{array}$} & \\
\cline { 2 - 3 } Tumor size, cm & No & Yes & P-value \\
\hline$<4.5$ & 22 & 1 & 1.000 \\
Mural nodule (-) & 3 & 0 & \\
Mural nodule (+) & & & 0.002 \\
$\geq 4.5$ & 21 & 3 & \\
Mural nodule (-) & 0 & 5 & \\
Mural nodule (+) & 46 & 9 & \\
Total & & & \\
\hline
\end{tabular}

pancreatectomy, as long-term survival is expected only if surgery can be performed prior to the MCN developing invasive malignant characteristics. In addition, function-preserving minimally invasive surgical approaches would be ideal for a select group of patients. Routine medical check-ups and the wider availability of axial imaging procedures have contributed to the increasing numbers of asymptomatic and smaller MCNs of the pancreas being found (1), which is consistent with the results in the present study. As the majority of MCNs of the pancreas are located in the pancreatic body and tail, minimally invasive pancreatectomy is an appropriate surgical approach; this is since laparoscopic distal pancreatectomy, with or without splenectomy, is regarded as a safe and effective treatment option for benign and borderline malignant tumors of the pancreas (25-28).

The perioperative outcomes of a minimally invasive approach to MCNs of the pancreas are comparable to those of conventional open surgery (Table III). In the present study, MIS exhibited a significantly increased duration of surgery (316.3 \pm 152.1$)$ compared with that of conventional surgery (208.3 $\pm 95.4 \mathrm{~min})(\mathrm{P}<0.05)$. However, a difference of $100 \mathrm{~min}$ may not be clinically significant, considering the fact that attempts to achieve spleen-preserving are increasing. When considering distal pancreatectomy, which was the most frequent surgical procedure performed, it is particularly noteworthy that there are several different clinical characteristics between two institutions from different countries.

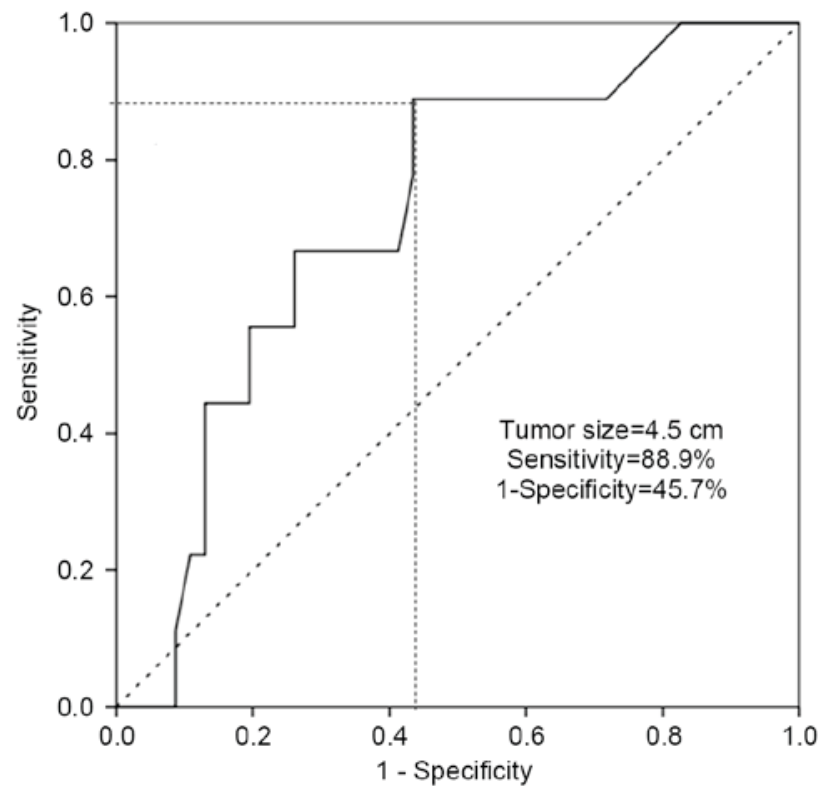

Figure 3. Receiver operating characteristic curve. A tumor size of $>4.5 \mathrm{~cm}$ was identified to predict malignant transformation of mucinous cystic neoplasm with an $88.9 \%$ sensitivity and a $45.7 \%$ false-positive rate (1-specificity).

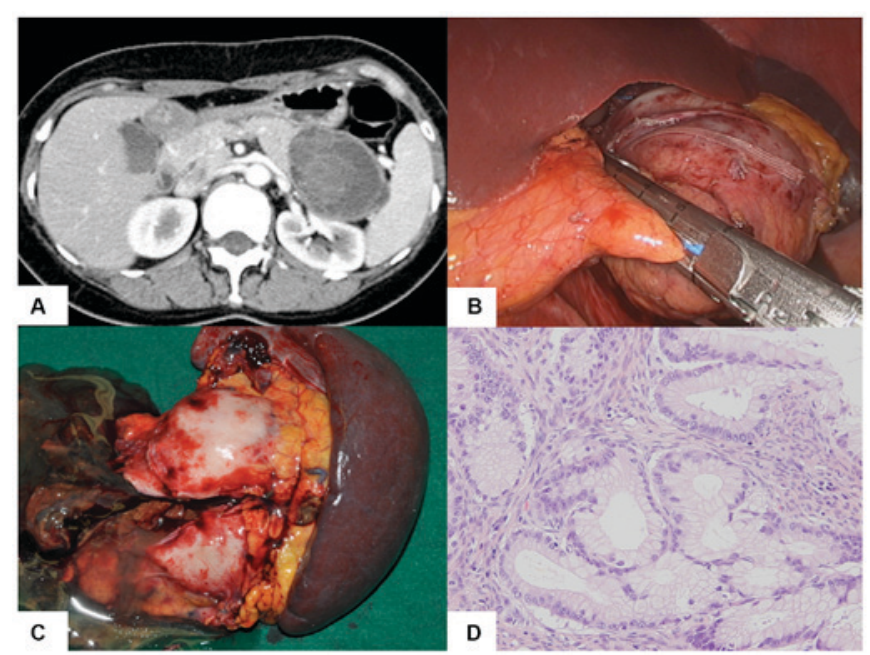

Figure 4. Representative images of a 40-year-old female patient with a 6 -cm cystic tumor in the distal region of the pancreas. (A) An intracystic solid component without invasive characteristics were identified in preoperative images [computed tomography (shown), magnetic resonance cholangiopancreatography and endoscopic ultrasound]. (B) Laparoscopic 50\% distal pancreatectomy with splenectomy was performed. Spleen-preservation was avoided due to close proximity of the tumor to the splenic hilum and splenic vessels. (C) Resected specimen showing a mucinous bloody component with intracystic small solitary lesions. (D) Pathological examination (hematoxylin and eosin stain; magnification, $\mathrm{x} 400$ ) revealed the resected cystic tumor of the pancreas was a borderline mucinous cystic neoplasm. This patient was expected to exhibit long-term survival and minimally invasive pancreatectomy was an appropriate approach.

These observations may be due to different clinical situations, such as the individual medical insurance systems of the two institutions; however, despite the differences, the two institutions dictate the use of a minimally invasive approach.

A previous study of $179 \mathrm{MCN}$ cases revealed that a large tumor size was associated with an increased risk for 


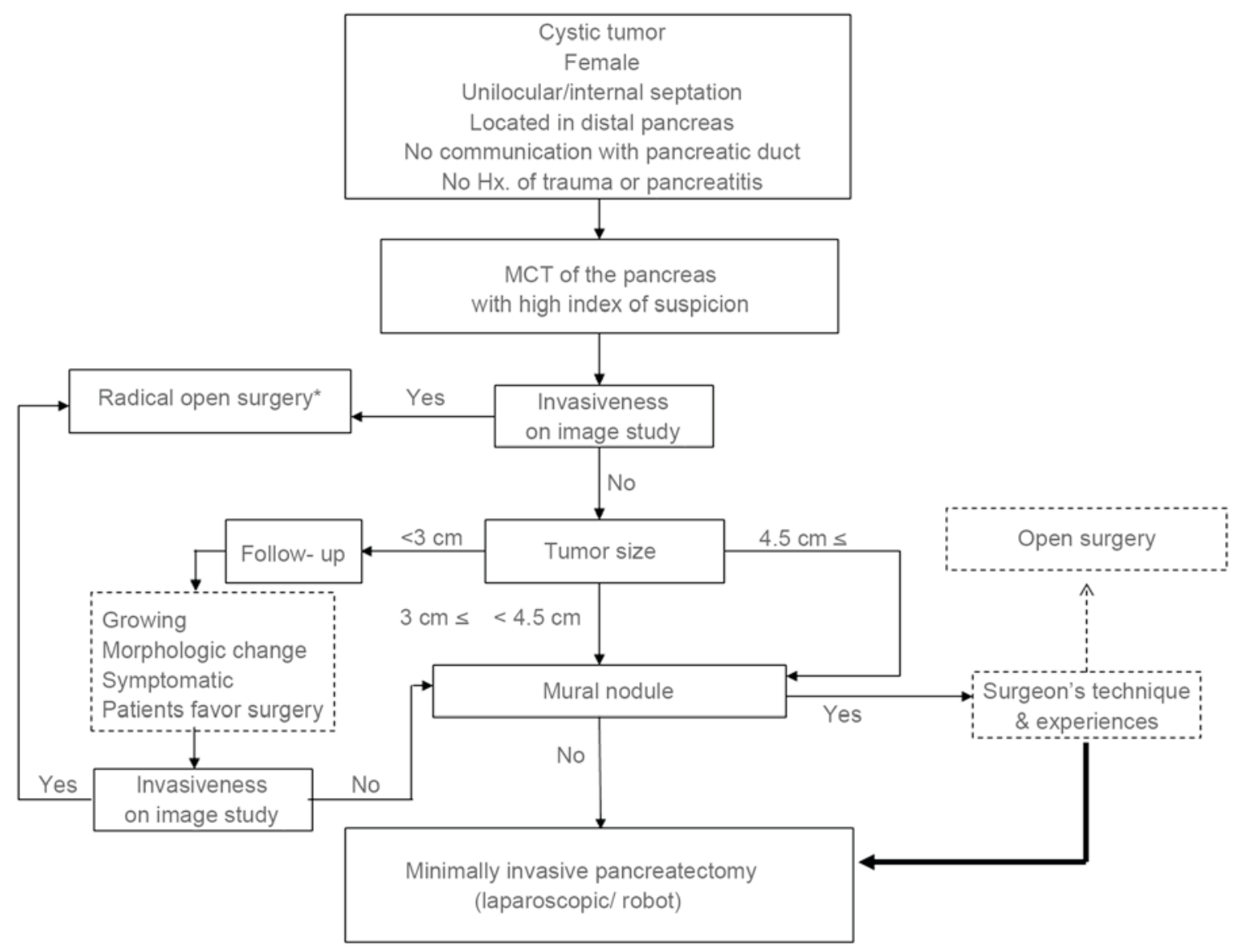

Figure 5. Strategy to MCN of the pancreas based on bi-institutional surgical experiences. According to experiences of surgeons at the two institutions, an active minimally invasive approach to $\mathrm{MCN}$ of the pancreas is recommended, as non-invasive pancreatic MCN is not aggressive. Minimally invasive radical pancreatectomy may be considered even in select cases. Asterisk indicates radical open surgery, open pancreatectomy with lymph node dissection. MCN, mucinous cystic neoplasm.

malignancy (29). As demonstrated in patients with intraductal papillary mucin-producing tumors of the pancreas, the cyst size of the tumor was associated with malignant transformation (6,30-32). Typically, a size of $3-4 \mathrm{~cm}$ is suggested to be a cut-off value for determining the malignant potential of $\mathrm{MCN}$ of the pancreas $(6,12,33)$. Although there was a limited number of cases, the results of the present study demonstrated that a tumor size of $>4.5 \mathrm{~cm}$ was a preoperative parameter that may be used to predict the malignant transformation of MCN of the pancreas, with $88.9 \%$ sensitivity and a $45.7 \%$ false-positive rate (AUC, 0.719; $\mathrm{P}=0.039$; Fig. 3). In addition, it was suggested that preoperative detectable mural nodules were a reliable preoperative parameter for the prediction malignant transformation in $\mathrm{MCN}$ of the pancreas $(\mathrm{P}=0.002)$. A tumor $>4.5 \mathrm{~cm}$ combined with an intracystic solid portion (mural nodule) were associated with malignant transformation $(\mathrm{P}=0.002$; Table V). Yamao et al (24) demonstrated that the presence of a large cystic tumor $(60,1 \pm 38.0$ vs. $90.0 \pm 45.5 \mathrm{~mm}$, $\mathrm{P}<0.001)$ and the presence of a nodule $(28 / 129$ vs. $14 / 27$, $\mathrm{P}=0.003$ ) were observed at a higher frequency in mucinous cystadenocarcinoma compared with that in mucinous cyst adenoma. Therefore, it may be appropriate to consider the tumor size and the presence of mural nodules together in predicting the malignant potential in MCNs of the pancreas.

On the basis of the present study, minimally invasive pancreatectomy may be selected for small MCNs $(<4.5 \mathrm{~cm})$ without an invasive component in preoperative imaging studies. The minimally invasive approach may additionally be considered for radical pancreatectomy in selected cases (34-37). According to the technique and experience of the surgeon involved, active minimally invasive pancreatectomy can be applied in non-invasive MCN of the pancreas regardless of tumor size. If there are no definitive invasive characteristics identified in preoperative images, even a large tumor $(\geq 4.5 \mathrm{~cm})$ with a mural nodule may be a candidate for the minimally invasive approach, according to results of the present study (Figs. 4 and 5). However, the risk of a rupture of the cyst during the laparoscopic approach may increase in cases of large MCNs and may lead to tumor metastasis. Nakamura et al (38) demonstrated a safe surgical technique for laparoscopic distal pancreatectomy involving a large cystic tumor based on securing sufficient working space and minimizing intraperitoneal cystic fluid spillage. Previous studies have suggested a surgical technique for spleen-preserving laparoscopic or robotic subtotal pancreatectomy with segmental resection of whole splenic vessels to avoid cystic rupture during dissection $(39,40)$. Therefore, patient selection and the surgical approach are important.

In summary, pancreatic cystic tumors are a heterogeneous disease. However, unique clinical presentations and advanced radiological experience can reveal an appropriate preoperative diagnosis of MCNs of the pancreas. A tumor size of $>4.5 \mathrm{~cm}$ with the presence of a mural nodule may predict the malignant 
change of pancreatic MCNs. However, the majority of cystic tumors of the pancreas with well-defined boundaries of cystic walls without local invasion in preoperative imaging are considered to be benign or borderline MCNs with or without focal non-invasive carcinomatous transformation. Therefore, minimally invasive and function-preserving pancreatectomy may be initially recommended.

\section{Acknowledgements}

This abstract was presented at the 26th World Congress of the International Association of Surgeons, Gastroenterologists and Oncologists, September 8-10, 2016 in Seoul, Republic of Korea, and was published as Abstract no. PP2-012 in Dig Surg 33 (Suppl 1): 1-232, 2016.

\section{References}

1. Edirimanne $\mathrm{S}$ and Connor SJ: Incidental pancreatic cystic lesions. World J Surg 32: 2028-2037, 2008.

2. Fernández-del Castillo C and Warshaw AL: Cystic tumors of the pancreas. Surg Clin North Am 75: 1001-1016, 1995.

3. Lester T, Robert B, Ronald P, et al: Mucinous cystic neoplasm (mucinous cystadenocarcinoma of low-grade malignant potential) of the pancreas: A clinicopathologic study of 130 cases. Am J Surg Pathol 23: 1-16, 1999.

4. Kloppel G, Solcia E, Longnecker DS, Capella L and Sobin LH: Histological typing of tumor of the exocrine pancreas. In: World Health Organization. International Histological Classification of Tumors. Springer, Berlin, Heidelberg, New York, NY, 1996.

5. Zamboi G KG, Hruban RH, Longnecker DA and Adler G: Mucinous cystic neoplasms of the pancreas. In: Pathology and Genetics of Tumors of the Digestie System. World Health Organization Classification of Tumors. Hamilton SR, and Aaltonen LA (eds). IARC press, Lyon, pp234-236, 2000.

6. Tanaka M, Chari S, Adsay V, Fernandez-del Castillo C, Falconi M, Shimizu M, Yamaguchi K, Yamao K and Matsuno S International Association of Pancreatology: International consensus guidelines for management of intraductal papillary mucinous neoplasms and mucinous cystic neoplasms of the pancreas. Pancreatology 6: 17-32, 2006.

7. Yoon WJ, Lee JK, Lee KH, Ryu JK, Kim YT and Yoon YB: Cystic neoplasms of the exocrine pancreas: An update of a nationwide survey in Korea. Pancreas 37: 254-258, 2008.

8. Zamboni G, Scarpa A, Bogina G, Iacono C, Bassi C, Talamini G, Sessa F, Capella C, Solcia E, Rickaert F, et al: Mucinous cystic tumors of the pancreas: Clinicopathological features, prognosis, and relationship to other mucinous cystic tumors. Am J Surg Pathol 23: 410-422, 1999.

9. Sarr MG, Carpenter HA, Prabhakar LP, Orchard TF, Hughes S, van Heerden JA and DiMagno EP: Clinical and pathologic correlation of 84 mucinous cystic neoplasms of the pancreas: Can one reliably differentiate benign from malignant (or premalignant) neoplasms? Ann Surg 231: 205-212, 2000.

10. Wilentz RE, Albores-Saavedra J, Zahurak M, Talamini MA, Yeo CJ, Cameron JL and Hruban RH: Pathologic examination accurately predicts prognosis in mucinous cystic neoplasms of the pancreas. Am J Surg Pathol 23: 1320-1327, 1999.

11. Wilentz RE, Albores-Saavedra J and Hruban RH: Mucinous cystic neoplasms of the pancreas. Semin Diagn Pathol 17: 31-42, 2000

12. Crippa S, SalviaR, Warshaw AL, Domínguez I,Bassi C,Falconi M, Thayer SP, Zamboni G, Lauwers GY, Mino-Kenudson M, et al: Mucinous cystic neoplasm of the pancreas is not an aggressive entity: Lessons from 163 resected patients. Ann Surg 247: 571-579, 2008

13. Hruban R, Kloppel G, Boffetta P, et al: Tumours of the pancreas. In: WHO Classification of Tumours of the Digestive System. Bosman FT, Carneiro F, Hruban RH and Theise ND (eds). 4th edition. IARC press, Lyon, pp280-330, 2010.

14. Bassi C, Dervenis C, Butturini G, Fingerhut A, Yeo C, Izbicki J, Neoptolemos J, Sarr M, Traverso W and Buchler M; International Study Group on Pancreatic Fistula Definition: Postoperative pancreatic fistula: An international study group (ISGPF) definition. Surgery 138: 8-13, 2005.
15. Wente MN, Veit JA, Bassi C, Dervenis C, Fingerhut A, Gouma DJ, Izbicki JR, Neoptolemos JP, Padbury RT, Sarr MG, et al: Postpancreatectomy hemorrhage (PPH): An International Study Group of Pancreatic Surgery (ISGPS) definition. Surgery 142: 20-25, 2007.

16. Simoes PK, Olson SH, Saldia A and Kurtz RC: Epidemiology of pancreatic adenocarcinoma. Chin Clin Oncol 6: 24, 2017.

17. Jemal A, Siegel R, Ward E, Murray T, Xu J, Smigal C and Thun MJ: Cancer statistics, 2006. CA Cancer J Clin 56: 106-130, 2006.

18. Matsumoto Y, Yamada E, Kamei S, Iwahara M and Ueoka R: High affinity of hybrid liposomes for normal human epidermal keratinocytes in vitro. Biol Pharm Bull 17: 1299-1300, 1994.

19. Pingpank JF, Hoffman JP, Ross EA, Cooper HS, Meropol NJ, Freedman G, Pinover WH, LeVoyer TE, Sasson AR and Eisenberg BL: Effect of preoperative chemoradiotherapy on surgical margin status of resected adenocarcinoma of the head of the pancreas. J Gastrointest Surg 5: 121-130, 2001.

20. Le Borgne J, de Calan L and Partensky C: Cystadenomas and cystadenocarcinomas of the pancreas: A multiinstitutional retrospective study of 398 cases. French surgical association. Ann Surg 230: 152-161, 1999.

21. Jimenez RE, Warshaw AL, Z'graggen K, Hartwig W, Taylor DZ, Compton CC and Fernández-del Castillo C: Sequential accumulation of K-ras mutations and p53 overexpression in the progression of pancreatic mucinous cystic neoplasms to malignancy. Ann Surg 230: 501-511, 1999.

22. Yeo CJ, Cameron JL, Sohn TA, Lillemoe KD, Pitt HA, Talamini MA, Hruban RH, Ord SE, Sauter PK, Coleman J, et al: Six hundred fifty consecutive pancreaticoduodenectomies in the 1990s: Pathology, complications, and outcomes. Ann Surg 226: 248-260, 1997.

23. Ridder GJ, Maschek H and Klempnauer J: Favourable prognosis of cystadeno- over adenocarcinoma of the pancreas after curative resection. Eur J Surg Oncol 22: 232-236, 1996.

24. Yamao K, Yanagisawa A, Takahashi K, Kimura W, Doi R, Fukushima N, Ohike N, Shimizu M, Hatori T, Nobukawa B, et al: Clinicopathological features and prognosis of mucinous cystic neoplasm with ovarian-type stroma: A multi-institutional study of the Japan pancreas society. Pancreas 40: 67-71, 2011.

25. Vijan SS,AhmedKA,Harmsen WS, QueFG, Reid-LombardoKM, Nagorney DM, Donohue JH, Farnell MB and Kendrick ML: Laparoscopic vs open distal pancreatectomy: A single-institution comparative study. Arch Surg 145: 616-621, 2010.

26. Baker MS, Bentrem DJ, Ujiki MB, Stocker S and Talamonti MS: A prospective single institution comparison of peri-operative outcomes for laparoscopic and open distal pancreatectomy. Surgery 146: 635-645, 2009.

27. Kooby DA, Gillespie T, Bentrem D, Nakeeb A, Schmidt MC, Merchant NB, Parikh AA, Martin RC II, Scoggins CR, Ahmad S, et al: Left-sided pancreatectomy: A multicenter comparison of laparoscopic and open approaches. Ann Surg 248: 438-446, 2008.

28. Palanivelu C, Shetty R, Jani K, Sendhilkumar K, Rajan PS and Maheshkumar GS: Laparoscopic distal pancreatectomy: Results of a prospective non-randomized study from a tertiary center. Surg Endosc 21: 373-377, 2007.

29. Suzuki Y, Atomi Y, Sugiyama M, Isaji S, Inui K, Kimura W, Sunamura M, Furukawa T, Yanagisawa A, Ariyama J, et al: Cystic neoplasm of the pancreas: A Japanese multiinstitutional study of intraductal papillary mucinous tumor and mucinous cystic tumor. Pancreas 28: 241-246, 2004.

30. Farnell MB: Surgical management of intraductal papillary mucinous neoplasm (IPMN) of the pancreas. J Gastrointest Surg 12: 414-416, 2008.

31. Jang JY, Kim SW, Lee SE, Yang SH, Lee KU, Lee YJ, Kim SC, Han DJ, Choi DW, Choi SH, et al: Treatment guidelines for branch duct type intraductal papillary mucinous neoplasms of the pancreas: When can we operate or observe? Ann Surg Oncol 15: 199-205, 2008.

32. Okabayashi T, Kobayashi M, Nishimori I, Sugimoto T, Namikawa T, Okamoto K, Okamoto N, Kosaki T, Onishi S and Araki K: Clinicopathological features and medical management of intraductal papillary mucinous neoplasms. J Gastroenterol Hepatol 21: 462-467, 2006.

33. Reddy RP, Smyrk TC, Zapiach M, Levy MJ, Pearson RK, Clain JE, Farnell MB, Sarr MG and Chari ST: Pancreatic mucinous cystic neoplasm defined by ovarian stroma: Demographics, clinical features, and prevalence of cancer. Clin Gastroenterol Hepatol 2: 1026-1031, 2004. 
34. Choi SH, Kang CM, Hwang HK, Lee WJ and Chi HS: Robotic anterior RAMPS in well-selected left-sided pancreatic cancer. J Gastrointest Surg 16: 868-869, 2012.

35. Choi SH, Kang CM, Lee WJ and Chi HS: Multimedia article Laparoscopic modified anterior RAMPS in well-selected left-sided pancreatic cancer: Technical feasibility and interim results. Surg Endosc 25: 2360-2361, 2011.

36. Fernández-Cruz L, Cosa R, Blanco L, Levi S, López-Boado MA and Navarro S: Curative laparoscopic resection for pancreatic neoplasms: A critical analysis from a single institution. J Gastrointest Surg 11: 1607-1622, 2007.

37. Song KB, Kim SC, Park JB, Kim YH, Jung YS, Kim MH, Lee SK, Seo DW, Lee SS, Park DH and Han DJ: Single-center experience of laparoscopic left pancreatic resection in 359 consecutive patients: Changing the surgical paradigm of left pancreatic resection. Surg Endosc 25: 3364-3372, 2011.
38. Nakamura Y, Matsumoto S, Tajiri T and Uchida E: Safe technique for laparoscopic distal pancreatectomy involving a large cystic tumor. J Nippon Med Sch 78: 374-378, 2011.

39. Choi SH, Kang CM, Kim JY, Hwang HK and Lee WJ Laparoscopic extended (subtotal) distal pancreatectomy with resection of both splenic artery and vein. Surg Endosc 27: 1412-1413, 2013.

40. Kim DH KC, Hwang HK, Lee WJ and Chi HS: 'Extended' distal pancreatectomy with segmental resection of both splenic vessels: Extended Warshaw's procedure. Korean J Hepatobiliary Pancreat Surg 14: 5, 2010. 